\title{
URGENSI MASLAHAH DALAM KONSEP EKONOMI SYARIAH
}

\author{
Sakirman \\ STAIN Jurai Siwo Metro Lampung \\ Jl. Ki Hajar Dewantara 15A Kampus Kota Metro - Lampung, 34111 \\ E-mail : sakirman87@gmail.com
}

\begin{abstract}
The fragility of the economic system of capitalism and socialism makes the Islamic economic system into an alternative economic system and studied in depth by contemporary Islamic economic thinkers. In realizing Islamic economic system must be aligned with the maqasid alshari'ah (goals sharia). There are four main approaches in the study of Islamic economics namely: a pragmatic approach, recitative, utopian and adaptive. Such an approach always leads to moral values, human brotherhood, social justice, integrating Islamic values and aims for the establishment of al-mashlahah as the core maqashid al-shari'ah can be used as an argument of the legal establishment, especially relating to Islamic economics. Ijtihad in Islam economy by using al-maslahah can be done by meeting certain requirements that do not conflict with al-Qur'an and al-Hadith and not contrary to qiyas. Besides, it does not conflict with a higher benefit, both in how to do it and in a way to preserve from extinction. Economic Ijtihad Islam implemented by analyzing the social and political realities and priorities (fiqh figh realities and priorities) in order to achieve the benefit of society and the state.
\end{abstract}

Keywords : mashlahah, Islamic economics, maqashid as-Sharia, production, consumption, distribution

\begin{abstract}
Abstrak
Kerapuhan sistem ekonomi kapitalisme dan sosialisme menjadikan sistem ekonomi Islam menjadi sistem ekonomi alternatif dan dikaji secara mendalam oleh pemikir ekonomi Islam kontemporer. Dalam mewujudkan sistem ekonomi Islam harus selaras dengan maqashid alshari'ah (tujuan-tujuan syari'ah). Ada empat pendekatan utama dalam kajian tentang ekonomi Islam yakni: pendekatan pragmatis, resitatif, utopian dan adaptif. Pendekatan tersebut selalu mengarah kepada nilai-nilai moral, persaudaraan kemanusiaan, keadilan sosial, mengintegrasikan nilai-nilai keislaman dan bertujuan untuk terwujudnya al-Mashlahah sebagai inti maqashid al-shari'ah dapat digunakan sebagai dalil penetapan hukum khususnya yang berhubungan dengan ekonomi Islam. Ijtihad dalam ekonomi Islam dengan menggunakan al-mashlahah dapat dilakukan dengan memenuhi syarat tertentu yakni tidak bertentangan dengan al-Qur'an dan al-Hadis serta tidak bertentangan dengan qiyas. Disamping itu tidak bertentangan dengan kemaslahatan yang lebih tinggi, baik dalam cara mewujudkannya maupun dalam cara mempertahankan dari kemusnahannya. Ijtihad Ekonomi Islam diimplementasikan dengan menganalisa realitas sosial dan politik dan prioritas (fiqh realitas dan figh prioritas) untuk mencapai kemaslahatan masyarakat dan negara.
\end{abstract}

Kata kunci : mashlahah, ekonomi Islam, maqashid as-Syariah, produksi, konsumsi, distribusi 


\section{8 | Sakirman}

\section{PENDAHULUAN}

Kebebasan lekat dengan manusia baik kebebasan berfikir dan kebebasan berkehendak. Kebebasan, kemudian menjadikan manusia sebagai wakil Tuhan di muka bumi. Ia berkuasa atas apa saja yang ada di bumi, bahkan seisi alam raya yang bertaburan di cakrawala. Ilmu pengetahuan sebagai alat eksplorasi mengukuhkan posisi manusia di atas segalanya. Gagasan demi gagasan dan temuan demi temuan semuanya memapankan eksistensi manusia. Namun demikian, eksistensi manusia alih-alih meruntuhkan nilai luhur kemanusiaan itu sendiri. Terlebih abad ini agama menjadi satu mata rantai dengan kekuasaan dan penguasaan.

Akhir-akhir ini, lembaga perbankan dan keuangan syariah mengalami kemajuan yang sangat pesat. Lembaga-lembaga perbankan yang dimaksud antara lain asuransi, sukuk, pegadaian, mortgage, leasing dan multifinance, capital market, mutual fund, factoring, MLM (Multi Level Marketing), dsb. Perkembangan sains dan teknologi modern telah menimbulkan dampak besar terhadap kehidupan manusia, khususnya terhadap kegiatan ekonomi bisnis, seperti tata cara perdagangan melalui e-commerce, system pembayaran dan pinjaman dengan kartu kredit, sms banking, perdagangan international / ekspor impor dengan media L/C, sampai kepada, instrumen pengendalian moneter, exchange rate, waqf saham, jaminan fiducia (rahn tasjiliy) dalam pembiayaan, jaminan resi gudang.

Kehadiran lembaga-lembaga perbankan dan keuangan syari'ah didasarkan kepada maslahah. Inovasi zakat produktif dan waqaf tunai juga didasarkan kepada maslahah. Pendeknya semua aktivitas dan perilaku dalam perekonomian acuannya adalah maslahah. Jika di dalamnya ada kemaslahatan, maka hal itu dibenarkan dan dianjurkan oleh syari'ah. Sebaliknya jika di sana ada kemudratan dan mafsadah, maka prakteknya tidak dibenarkan, seperti ihtikar, spekulasi valas dan saham,gharar, judi, dumping, dan segala bisnis yang mengandung riba. Demikian pula dalam membicarakan perilaku konsumen dalam kaitannya dengan utility. Dalam ekonomi konvensional, tujuan konsumen adalah untuk memaksimalkan utility, sedangkan dalam ekonomi Islam untuk memaksikumkan maslahah. Utility adalah sebuah konsep yang kepuasaan (manfaatnya) bersifat material dan keduniaan belaka, sedangkan maslahah adalah utility yang mengandung unsur-unsur akhirat, bersifat spiritual dan transendental.

Tulisan ini ingin memposisikan kembali fungsi agama (baca; Islam) laiknya awal kemunculannya seperti yang didaulat oleh Allah swt melalu syari'atNya. Selanjutnya, diulas mengenai hal ihwal kompromi antara agama dan ekonomi. Terakhir, akan dibahas tentang sekat-sekat kepentingan yang meruntuhkan nilai-nilai luhur agama dari sudut pandang ekonomi. 


\section{PEMBAHASAN}

Konsep Ekonomi Syariah

Syari'ah sebagai jalan menuju tercapainya nilai-nilai luhur Islam yang universal dan holistik kini berada di persimpangan jalan antara jalan sosialisme dan kapitalisme. Kebangkrutan perekonomian dunia ditengarai oleh ekonomi syari'ah karena ketiadaan keadilan yang menyeluruh. Ekonomi syariah dilandasi nilai-nilai luhur Islam dan merupakan sebuah studi ilmu sosial yang khusus mengkaji persoalan ekonomi masyarakat global. Hal yang paling membedakan dari sistem ekonomi syariah dengan sistem ekonomi kapitalisme, sosialisme, maupun negara kesejahteraan (Welfare State) adalah perlawanannya terhadap eksploitasi yang dilakukan oleh pemilik modal terhadap buruh yang miskin, dan melarang penumpukan kekayaan.

Ekonomi syari'ah kini ingin menegaskan kembali sembari menawarkan solusi-solusi yang mengakar dan tersistematis melalui nilai-nilai luhur Islam yang telah tebukti selama berabad-abad. Melalui empat pilarnya, ekonomi syari'ah hendak menjawab tantangan zaman, yaitu:

1. Kesatuan (unity)

2. Keseimbangan (equilibrium)

3. Kebebasan (free will)

4. Tanggung jawab (responsibility).

Empat pilar inilah yang akan menjadi "kemudi" roda ekonomi kehidupan masyarakat, sehingga keadilan ekonomi sosial bukan hanya isapan jempol semata.

\section{Konsep Maslahah}

Maslahah memiliki asal kata mas lahah, berasal dari bahasa 'arab diambil dari kata kerja shalaha-yassluhu menjadi sulhan-mashlahatan mengikuti wazan (pola) fa'ala-yaf'ulu yang berarti manfa'at, fâidah, bagus, guna atau kegunaan. Akar kata maslahah juga bisa berasal dari bentuk tunggal (mufrod) dari kata al-maŝâlih. Dalam lisân al-'Arob dijelaskan bahwa kata maslahah memiliki dua arti, yang pertama, al-mas lahah yang berarti alsholah dan yang kedua, al-mas lahah yang berarti bentuk tunggal dari almassâlih. Semuanya mengandung arti adanya manfa'at baik secara asal maupun melalui proses, seperti menghasilkan kenikmatan dan faedah, ataupun pencegahan dan penjagaan, seperti menjauhi kemadharatan dan penyakit. Semua itu bisa dikatan maslahah.

Sementara itu, kata maslahah dalam kamus besar bahasa Indonesia diartikan dengan sesuatu yang mendatangkan kebaikan (kemaslahatan dan sebagainya), faedah, guna. Sedangkan kata kemaslahatan diterjemahkan dengan kegunaan, kebaikan, manfaat atau kepentingan. 


\section{0 | Sakirman}

Secara istilah, maslahah dapat didefinisikan sebagai berikut:

Maslahah dalam pandangan al-Buthi adalah manfaat yang ditetapkan shâri' untuk para hambanya yang meliputi pemeliharaan agama, diri, akal, keturunan dan harta mereka sendiri sesuai dengan urutan tertentu. ${ }^{1}$ Selain itu al-Syaukâni menguraikan mas lahah lebih terperinci, karena menurut dia makna yang digunakan untuk mengistilahkan maslahah memiliki makna yang berbeda-beda. Mas lahah adakalanya disebut al-munâsabah karena untuk mendapatkan kepastian hukum dari permasalahan yang tidak ada dalilnya seseorang dapat melakukan munâsabah, yaitu membandingkan dengan permasalahan nas al-Qur'an. Adakalanya maślahah disebut dengan al-Halât, karena mungkin juga manusia menduga-duga adanya kemanfaatan dibalik suatu hukum. Mas lahah disebut dengan ri'âyah al-maqâsid. Karena dengan mewujudkan kemaslahatan berarti mewujudkan dan menjaga tujuan shara', yaitu kemaslahatan umum. ${ }^{2}$ Lebih jelasnya ia berpendapat bahwa maslahah adalah sesuatu yang perlu untuk dilestarikan dan sejalan dengan keinginan manusia untuk menarik manfat dan menolak bahaya. Kemudian Al-Syâtibi, salah satu Ulama' Madzhab Maliki mengatakan bahwa maslahah adalah setiap prinsip shara' yang tidak disertai nas khusus, namun sesui dengan tindakan shara' serta maknanya diambil dari dalil-dali shara'. Makna prinsip tersebut adalah sah sebagai dasar hukum dan dapat dijadikan bahan rujukan sepanjang ia telah menjadi prinsip dan digunakan oleh shara' yang $q a \underline{t}^{\prime} \hat{i}^{3}$

Dia mengklasifikasikan masslahah menjadi dua bagian , masslahah dari keberadaannya didunia dan dari aspek hubungannya dengan statemen shâri'ah (khitâb shâri'ah). Dalam kaitanya dengan keberadaanya didunia, maslahah berarti sesuatu yang membicarakan penegakan kehidupan manusia dan pencapaian segala sesuatu yang dianut oleh kualitaas intelektual dan emosinya. Oleh karena itu dalam dataran praktis, mas $l a \underline{h} a h$ berhubungan erat dengan sesuatu yang lazim di masyarakat yang disebut adat. Sedangkan dari aspek kedua, segala sesuatunya kembali lagi keketentuan ketentuan shâri'ah. Dalam hal ini, apabila shâri' menuntut sesuatu itu dikerjakan oleh manusia berarti masla $\underline{h} a h$ dan apabila dilarang berarti mafsadah.

${ }^{1}$ Said Ramadhan Al-Buthi, Dhawabit Al-Maslahah Fi Al-Shari'ah Al-Islamiyah (Bairut: Muassah Al-Risalah, 1977).

${ }^{2}$ Al-Syaukani, Irsyad Al-Fuhu (Bairut: Dar al-Fikr, n.d.).

${ }^{3}$ Abu Ishaq bin Musa bin Muhammad Al-Syatibi, Al-Mustafa (Bairut: Dar al-Tsaqofah, n.d.).

PALITA: Journal of Social-Religi Research 
Adapun menurut al-Ghazâlî, dijelaskan bahwa secara harfiah mas lahah adalah menarik kemanfaatan dan menghindarkan kerugian. Namun yang dikehendaki dalam pembahasan masslahah ini bukanlah pengertian tersebut, akan tetapi melestarikan tujuan-tujuan shâri'at. Seadangkan tujuan shâri'at pada makhluk mencakup lima hal, memelihara agama, jiwa, akal, keturunan dan harta kekayaan. Karenanya setiap hal yang memiliki muatan pelestarian terhadap lima prinsip dasar ini adalah maslahah. Sendangkan hal-hal yang menghambat pencapaian prinsip-prinsip ini disebut mafsadah, dan menolalak atas mafsadah adalah suatu maslahah. ${ }^{4}$

Mustafa Syalbi, menyimpulkan masslahah kedalam dua pengertian. Pertama, dengan pengertian majas, maslahah adalah sesuatu yang menyampaikan pada kemanfaatan. Kedua, secara hakiki, mas lahah adalah akibat itu sendiri yang timbul dari sebuah tindakan, yaitu berupa kebaikan atau kaemanfaatan.

Kemudian pengertian maslahah menurut al-Tûfî, didefinisikan menurut 'urf (pemahaman umum yang berlaku di masyarakat) adalah sebab yang membawa pada kemaslahatan (manfaat). Dengan demikian al-Tûfî ingin menegaskan bahwa maslahah yang ingin di kehendaki hukum islam tidak sama dengan apa yang dikehendaki manusia.

Terakhir, pengertian maslahah menurut Wahbah al-Zuhaili. Dia memberikan sebuah definisi yang dianggap akomodatif dan dapat menjelaskan hakikat maslahah, ia menuturkan bahwa maslahah adalah karakter yang memiliki keselarasan dengan perilakau penetapan shâri'ah dan tujuan-tujuannya, namun tidak ada dalil secara spesifik mengungkapkan atau menolaknya, dengan proyeksi mewujudkan kemaslahatan dan menghilangkan mafsadah (kerusakan). ${ }^{5}$

Dari beberapa definisi tersebut, tampak yang mejadi tolok ukur maslahah adalah tujuan-tujuan shara' atau berdasarkan ketetapan shâri'. Meskipun kelihatan bertentangan dengan tujuan manusia yang sering kali dilandaskan pada hawa nafsu semata, semua definisi tersebut sesungguhnya masih dalam koridor syari'at. Hanya saja antara satu dengan yang lain berbeda dalam hal mengungkapkan artikulasi bahasanya. Berdasarkan pengertian tersebut, hemat penulis maslahah itu merupakan variabel bebas yang nilai-nilainya terikat oleh keuniversalan manfaat yang telah termaktub di dalam wahyu.

${ }^{4}$ Abu Hamid bin Muhammad bin Muhammad Al-Ghazali, Al-Mustafa Min 'Ilmi Ushul, Juz II (Bairut: Dar al-Fikr, n.d.).

${ }^{5}$ Wahbah Al-Zuhaili, Ushul Al-Fiqh Al-Islami (Bairut: Dar al-Fikr, n.d.). 


\section{2 | Sakirman}

\section{Perilaku Manusia di Era Post-Modern}

Ruang dan akses komunikasi manusia di era Post-Modern (selanjutnya dibaca posmo) semakin meluas. Beberapa promo produk seringkali menggunakan teknologi informasi, sehingga penipuan sering kali terjadi. Akibatnya tidak jarang konsumen menderita kekecewaan. Hal ini dapat dilihat pada beberapa kasus kecil hingga kasus besar yang berkedok "syariah" menggegerkan ekonomi dunia. Fenomena tersebut jika dibaca secara seksama mengindikasikan bahwa ekonomi syari'ah terlampau diterima oleh masyarakat.

Jika dicermati dari kemunculan ekonomi Islam abad modern ini, ia tampak sebagai "jalan baru" di persimpangan jalan buntu. Dikatakan demikian, karena muatan yang terkandung di dalamnya lebih bersifat materialistik. Perayaan mengenai prakteknya diramaikan oleh beberapa kalangan seperti akademisi, praktisi, bahkan ada peran strategis dari negara (pemerintah). Sampai di sini, kajian mengenai paradigma maslahah dalam ekonomi syari'ah menjadi perlu sebagai bentuk ikhtiyar dalam menemukan sumbu maslahah yang selama ini terpendam oleh sistem yang masih bersifat materialistik. Selanjutnya, penulis ingin mengurai paradigma maslahah dalam ekonomi syari'ah yang meliputi paradigma maslahah dalam produksi, paradigma maslahah dalam konsumsi dan paradigma maslahah dalam distribusi.

\section{Paradigma Maslahah dalam Produksi}

Produksi memiliki makna yang sama dengan eksplorasi yaitu pengerukan sumber daya alam melalui ilmu pengetahuan yang dikembangkan manusia. Islam memandang produksi sebagai sarana yang dapat mengantarkan kepada keluhuran moral manusia. Karena tujuan akhir tersebut diutamakan ketimbang kesenangan sementara, yakni kehidupan akhirat. Sehingga pemenuhan produksi lebih diartikan sebagai pemenuhan saving untuk kehidupan yang abadi.

Al-quran dalam Surat As-Sajdah ayat 2 menjelaskan:

"Dan apakah mereka tidak memperhatikan, bahwasanya kami menghalau (awan yang mengandung) air ke bumi yang tandus, lalu kami tumbuhkan dengan air hujan itu tanaman yang daripadanya makan hewan ternak mereka dan mereka sendiri. Maka apakah mereka tidak memperhatikan?". 
Ayat tersebut menjelaskan tentang tanah yang berfungsi sebagai penyerap air hujan dan akhirnya tumbuh tanaman-tanaman yang terdiri dari beragam jenis. Tanaman itu dapat dimanfaatkan manusia sebagai faktor produksi alam, dari tanaman tersebut juga dikonsumsi oleh hewan ternak yang pada akhirnya juga hewan ternak tersebut diambil manfaatnya (diproduksi) dengan berbgai bentuk seperti diambil dagingnya, susunya dan lain sebagaiya yang ada pada hewan ternak tersebut.

Ayat tersebut seolah mengisyaratkan agar manusia memikirkan siklus kehidupan. Maksud terdalam ayat ini dapat dipahami bahwa ketika produksi tidak memedulikan faktor keseimbangan alam, maka siklus tidak bisa berjalan secara normal. Dan, ketika itu kesengsaraan atau kekacauan menjadi niscaya. Jelas, ayat tersebut tidak menyetujui adanya ketimpangan margin humaniti yang disebabkan oleh pemaksimalan margin ekonomi. Kelangkaan, kenaikan harga, pemutusan kerja dan lain sebagainya adalah akibat dari pemaksimalan margin ekonomi. Di sinilah perlunya paradigma maslahah dalam produksi ekonomi syari'ah.

\section{Paradigma Maslahah dalam Konsumsi}

Konsumsi merupakan satu tali dengan produksi. Dimana diproduksi suatu barang disitulah kebutuhan konsumen tersedia. Islam sebagai panduan hidup telah menggariskan batas-batas konsumsi. Bahkan dalam al-Qur'an dijelaskan:

"Dan jika kami hendak membinasakan suatu negeri, Maka kami perintahkan kepada orang-orang yang hidup mewah di negeri itu (supaya mentaati Allah) tetapi mereka melakukan kedurhakaan dalam negeri itu, Maka sudah sepantasnya berlaku terhadapnya perkataan (ketentuan kami), Kemudian kami hancurkan negeri itu sehancurhancurnya." (QS. Al-Isra: 16)

Konsumerisme sangat bertentangan dengan ajaran Islam. Hal ini dapat dipahami melalui bahwa produksi yang berlebih pasti merusak siklus alam. Semakin alam diekploitasi, semakin rusak. Dan, pastinya semakin merebak kesenjangan sosial. Pada kondisi sedemikian, menurut sahabat Mu'awiyah, kuncinya adalah bagaimana kita mengatur anggaran pendapatan dan belanja rumah tangga. Pengaturan belanja yang baik itu merupakan setengah usaha, dan dia dianggap sebagai setengah mata pencaharian. Karena Islam menganjurkan umatnya untuk bekerja dan berusaha dengan baik di satu sisi. Dan, di sisi lain, Islam juga memerintahkan agar harta yang dikeluarkannya untuk tujuan yang baik dan bermanfaat (baca; maslahah) sebagai jalan mencapai kemuliaan di sisi Allah swt (baca; ibadah). 


\section{4 | Sakirman}

\section{Paradigma Maslahah dalam Distribusi}

Setelah produksi dan konsumsi, selanjutnya mengenai persoalan yang terkait dengan distribusi. Distribusi dalam hal ini lebih kepada distribusi penguasaan hak kepemilikan individu, sosial dan negara. Dalam Islam, masing-masing mempunyai peran dan fungsinya. Sebagai individu, wajib atasnya mengenai pendistribusian harta yang dimilikinya. Harta bisa berbentuk saham atau aset yang lain yang dapat dikembangkan dalam kerangka keadilan ekonomi bagi masyarakat luas. Sebagai masyarakat, wajib atasnya memelihara aset bersama guna menguatkan tali kemanusiaan dan keseimbangan alam agar tidak dieksploitasi secara seporadis. Sebagai negara, wajib baginya membuat aturan yang tidak monopoli kelas sosial yang satu dengan kelas sosial yang lain sehingga tercipta suatu keseimbangan baik keseimbangan pasar modal atau keseimbangan yang bersifat non-ekonomi seperti budaya dan politik.

\section{Paradigma Maslahah dalam Ekonomi Syari'ah}

Ekonomi syari'ah bukan sebuah konsep perpaduan antara kapitalisme dan sosialisme. Ia memiliki konsep yang mandiri, mengakar dan punya karakteristiknya sendiri baik mengenai ekonomi makro, ekonomi mikro, kebijakan moneter, kebijakan fiskal, pembiayaan publik ataupun tentang konsep pembangunan. Banyak anggapan yang mengatakan bahwa ekonomi syari'ah yaitu ekonomi konvensional minus riba plus ZIS. Pandangan ini terbantah, karena visi dan tujuan yang mendasari subjek ekonomi Islam tidak sama dengan ekonomi konvensional. Demikian pula pendefinisan kesejahteraan dalam subjek ekonomi Islam tidak sama dengan ekonomi konvensional.

Konsep kesejahteraan dalam literatur ekonomi konvensional misalnya, didefinisikan sebagai happines and life satisfaction. Konsep happiness ini selanjutnya dimasukkan kedalam terminologi material dan hedonistis, perolehan pendapatan dan profit yang tinggi untuk memenuhi biological needs. Dari konsep kesejahteraannya tersebut kemudian dapat dipahami bahwa aktifitas ekonomi konvensional hanya untuk melayani kecenderungan pribadi, kekayaan, kesenangan jasmani dan kepuasan sensual. Dengan begitu, 'value judgement' dalam ekonomi konvensional akan disingkirkan sehingga terjadi apa yang disebut dengan freedom to pursue self interest atau individu memiliki kebebasan memutuskan apa yang mereka inginkan. Pada kondisi yang seperti inilah keberadaan dan peran pemerintah dipersempit kecuali pada hal-hal yang menguntungkan para individu pemilik modal tersebut. 
Berbeda dengan apa yang digagas oleh Ibnu Khaldun mengenai konsep kesejahteraan. Ibnu Khaldun menggagas kesejahteraan tidak saja untuk pemenuhan kebutuhan dasar jasmani, melainkan juga kebutuhan nonmaterial. Salah satu kebutuhan non material yang paling penting adalah keadilan. Syarat kesejahteraan lainnya, menurutnya, adalah ketenangan mental, keharmonisan keluarga dan masyarakat, persaudaraan umat manusia, kebebasan, keamanan harta benda, keamanan hidup, minimisasi kejahatan dan penekanan.

Kesejahteraan merupakan produk akhir dari interaksi faktor-faktor ekonomi dengan faktor-faktor moral, sosial, demografis, politis dan historis yang terintegrasi sedemikian rupa sehingga masing-masing faktor tersebut tidak akan bisa berkontribusi optimum dengan menghilangkan salah satunya. Kesejahteraan yang hakiki mustahil akan pernah terealisasi tanpa adanya keadilan. Al-Qur'an telah menegaskan bahwa penegakan keadilan itu dasar tujuan diutusnya para rosul (QS.57:25):

"Sungguh, Kami telah mengutus rasul-rasul Kami dengan bukti-bukti yang nyata dan Kami turunkan bersama mereka kitab dan neraca (keadilan) agar manusia dapat berlaku adil".

Rosulullah saw juga pernah bersabda, "ketidakadilan sebagai kegelapan yang sesungguhnya". Hal demikian dikarenakan ketidakadilan dapat meruntuhkan solidaritas, karena ketidakadilan pun konflik akan sangat mudah disulut, ketidakadilan dapat juga menghilangkan rasa saling percaya serta dapat menyebabkan kerusakan sendi-sendi kehidupan manusia.

Terkait pentingnya penegakan sebuah keadilan, Abu Yusuf pernah menegaskan kepada Khalifah Harun Ar-Rasyid bahwa penegakan keadilan dan pembasmian ketidakadilan akan mempercepat pembangunan. Begitu pula dengan Al-Mawardi, beliau menyatakan bahwa keadilan akan meningkatkan solidaritas, penegakan hukum, pembangunan negara, peningkatan kekayaan, pertumbuhan penduduk dan keamaan negara. Dinyatakan pula "tidak ada yang dapat merusak dunia dan kemanusiaan manusia lebih cepat dari ketidakadilan". Tidak hanya itu, Ibnu Taimiyyah menyatakan keadilan adalah produk inti dari ketauhidan. Bahkan, Ibnu Khaldun sendiri menyatakan tidak mungkin membangun tanpa keadilan, ketidakadilan membawa kehancuran pembangunan, penurunan kesejahteraan adalah hasil dari pelanggaran keadilan. Dari definisi kesejahteraan yang diadopsi suatu masyarakat, akan membawa perbedaan konfigurasi dan mekanisme alokasi dan distribusi sumberdaya yang terbatas tersebut. 


\section{6 | Sakirman}

Dari paparan tersebut, dapat dipahami bersama bahwa maslahat dalam ruang ekonomi syari'ah memiliki dua pengertian. Pertama maslahat yang bersifat non-materi. Dan kedua, maslahat yang bersifat materi. Keduanya harus saling menguatkan. Syed Nawad Haider Naqvi menawarkan framework atas persoalan yang sedang menimpa ekonomi umat Islam sebagai dasar pijak bagi solusi konseptual. Dengan bingkai kaidah syariah "Al-Ashlu fi alaf'âl al-taqayyudu bi al-hukm al-syar'i" (Prinsip dasar mengenai perbuatan manusia, adalah wajib terikat dengan syariah Islam), menurutnya ada tiga asas yang harus diperjuangkan dalam membangun paradigma ekonomi syariah, yakni nilai, etika dan dasar Islam.

Jika dikaitkan dengan konsep maslahah yang telah dibahas di muka, maka ekonomi syari'ah seharusnya lebih mengutamakan faktor non-materi ketimbang faktor materi. Reasoning atas ide ini bisa dibaca mengenai beberapa konsep produksi, konsumsi dan distribusi yang telah termaktub dalam al-Qur'an. Sejarah mengenai kebijakan fiskal yang dilakukan oleh nabi saw pun sangat mempraktekkan keutamaan nilai, moral dan dasar Islam. Meski tidak secara detail, runtut dan sistematis, al-Quran menjelaskan mengenai ekonomi syari'ah, melalui paradigma maslahah dalam arti luas, maka pesan al-Qur'an dan sunnah nabi saw tetap terpenuhi sejalan zaman dan teknologi informasi. Misalnya, pada kasus ketika para sahabat mendesaknya untuk menurunkan harga, nabi Muhammad Saw tetap berpeganag pada "teks" sehingga menolak untuk mencampuri persoalan harga di Madinah. Tetapi pada kondisiyang berbeda samasekali (baca; terbalik), misalnya terjadi distorsi harga di pasar, Ibnu Taimiyah memfatwakan bahwa pemerintah boleh campur tangan dalam masalah harga. Secara tekstual, Ibnu Taymiyah tampak "mengingkari" nash hadits Nabi Saw. Tetapi karena pertimbangan kemaslahatan, di mana situasi berbeda dengan masa Nabi, maka Ibnu Taymiyah memahami hadits tersebut secara kontekstual berdasarkan pertimbangan maslahah.

Demikian pula dengan menjamurnya lembaga-lembaga perbankan dan keuangan syari'ah yang didasarkan kepada maslahah. Seperti wacana zakat produktif dan waqaf tunai yang acuannya adalah maslahah. Sehingga bisa dimengerti bersama bahwa apapun model produksi, konsumsi atau distribusi yang bermuara pada kemaslahatan umum, maka hal itu dibenarkan dan dianjurkan oleh syari'ah. Sebaliknya, apapun bentuk inovasi yang dikembangkan meski berlabel "syari'ah" tetapi terdapat kemudratan dan mafsadah, maka praktek tersebut tidak dibenarkan, seperti ihtikar , spekulasi valas dan saham, gharar, judi, dumping, dan segala bisnis yang mengandung riba. 


\section{KESIMPULAN}

Maslahah merupakan konsep terpenting dalam pengembangan ekonomi Islam. Para ulama sepanjang sejarah senantiasa menempatkan maslahah sebagai pinsip utama dalam syariah. Maslahah merupakan tujuan dari syariah Islam. Tujuan syariah biasa dikenal dengan sebutan maqashid syariah. Prinsip utama dalam formulasi ekonomi Islam dan perumusan fatwa-fatwa serta produk keuangan adalah maslahah. Penempatan maslahah sebagai prinsip utama, karena mashlahah merupakan konsep yang paling penting dalam syariah, Dalam studi prinsip ekonomi Islam, maslahah ditempatkan pada posisi kedua, yaitu sesudah prinsip tawhid. Mashlahah adalah tujuan syariah Islam dan menjadi inti utama syariah Islam itu sendiri. Para ulama merumuskan maqashid syari'ah (tujuan syariah) adalah mewujudkan kemaslahatan.

Penerapan maslahah dalam ekonomi Islam (muamalah) memiliki ruang lingkup yang lebih luas dibanding ibadah. Ajaran Islam tentang muamalah umumnya bersifat global, karena itu ruang ijtihad untuk bergerak lebih luas. Ekonomi Islam yang menjadi salah satu bidang muamalah berbeda dengan ibadah murni (ibadah mahdhah). Ibadah bersifat dogmatik (ta'abbudi), sehingga sedikit sekali ruang untuk berijtihad. Ruang ijtihad dalam bidang ibadah sangat sempit. Lain halnya dengan ekonomi Islam (muamalah) yang cukup terbuka bagi inovasi dan kreasi baru dalam membangun dan mengembangkan ekonomi Islam.

Al mashlahah sebagai salah satu model pendekatan dalam ijtihad menjadi sangat vital dalam pengembangan ekonomi Islam dan siyasah iqtishadiyah (kebijakan ekonomi). Mashlahah adalah tujuan yang ingin diwujudkan oleh syariat. Mashlahah merupakan esensi dari kebijakankebijakan syariah (siyasah syar iyyah) dalam merespon dinamika sosial, politik, dan ekonomi. Maslahah 'ammah (kemaslahatan umum) merupakan landasan muamalah, yaitu kemaslahatan yang dibingkai secara syar'i, bukan semata-mata profit motive dan material rentability sebagaimana dalam ekonomi konvensional.

\section{DAFTAR PUSTAKA}

Agustianto. "Epistemologi Ekonomi Islam," n.d. www.pelita.or.id.

Al-Buthi, Said Ramadhan. Dhawabit Al-Maslahah Fi Al-Shari'ah Al-Islamiyah. Bairut: Muassah Al-Risalah, 1977.

Al-Ghazali, Abu Hamid bin Muhammad bin Muhammad. Al-Mustafa Min 'Ilmi Ushul, Juz II. Bairut: Dar al-Fikr, n.d.

Al-Syatibi, Abu Ishaq bin Musa bin Muhammad. Al-Mustafa. Bairut: Dar alTsaqofah, n.d. 


\section{8 | Sakirman}

Al-Syaukani. Irsyad Al-Fuhu. Bairut: Dar al-Fikr, n.d.

Al-Zuhaili, Wahbah. Ushul Al-Fiqh Al-Islami. Bairut: Dar al-Fikr, n.d.

Bakri, Asafri Jaya. Konsep Maqashid Syari'ah Menurut Al-Syatibi. Jakarta: Rajawali Press, 1996.

Jauhar, Ahmad Al-Mursi Husain. Maqashid Syariah. Jakarta: Amzah, 2010.

Nasution, Mustafa Edwin. Pengenalan Eksklusif Ekonomi Islam. Kencana Pr. Jakarta, 2006.

Romli, Muhammad Guntur. "Menggagas Fiqh Maqashid," n.d. www.islamlib.com. 
Sumber tambahan 6

Agustianto, Epistemologi Ekonomi Islam, dalam www.pelita.or.id Bakri, Asafri Jaya, Konsep Maqashid Syari'ah menurut al-Syatibi, Jakarta: Rajawali Press, 1996.

Jauhar, Ahmad Al-Mursi Husain, Maqashid Syariah, Jakarta: Amzah, 2010.

Mustafa Edwin Nasution, Pengenalan Eksklusif Ekonomi Islam, Jakarta: Kencana Prenada Media Group, 2006.

Romli, Muhammad Guntur, Menggagas Fiqh Maqashid dalam www.islamlib.com

\footnotetext{
${ }^{6}$ Agustianto, "Epistemologi Ekonomi Islam," n.d., www.pelita.or.id; Asafri Jaya Bakri, Konsep Maqashid Syari'ah Menurut Al-Syatibi (Jakarta: Rajawali Press, 1996); Ahmad Al-Mursi Husain Jauhar, Maqashid Syariah (Jakarta: Amzah, 2010); Mustafa Edwin Nasution, Pengenalan Eksklusif Ekonomi Islam, Kencana Pr (Jakarta, 2006); Muhammad Guntur Romli, “Menggagas Fiqh Maqashid," n.d., www.islamlib.com.
} 